\title{
Indications for coronary revascularisation: a Dutch perspective
}

\author{
Henk Rigter, Annejet P Meijler, Joseph McDonnell, Jan K Scholma, Steven J Bernstein
}

\begin{abstract}
Objective-To assess the appropriateness of indications for coronary artery bypass graft (CABG) surgery and percutaneous transluminal coronary angioplasty (PTCA).
\end{abstract}

Methods-A modified Delphi group judgement process with input from a panel of six interventional cardiologists and six cardiopulmonary surgeons. There was one clinician from each of the 12 tertiary referral heart centres in The Netherlands.

Main outcome measure-Ratings by panel members, on a 1 to 9 scale, of indications presented as a choice between two treatments (CABG $v$ medical treatment, PTCA $v$ medical treatment, and CABG $v$ PTCA) for 1182 model cases. Each case represented a unique combination of clinical features in terms of symptoms, medical history, and results of tests. Ratings were analysed with respect to degree of agreement among panelists, degree of appropriateness of indications, and panel's preference for invasive or medical treatment.

Results-The panel agreed on $58.6 \%$ and disagreed on $3.2 \%$ of the indications. The panel opted for invasive treatment in $48.2 \%$ and medical treatment in $22.8 \%$, and had no clear preference for either method in $29.0 \%$ of the cases. When compared with medical treatment, CABG was more often rated appropriate than PTCA: $35.4 \%$ v 21.6\% (P< 0.001). Panel scores depended on severity of anatomical disease. For instance, for $51.5 \%$ of the model cases with one-vessel disease not including the proximal left anterior descending artery, the panel preferred medical treatment to invasive treatment, while the latter was preferred in $18 \%$ of the cases. In cases with type $C$ lesions, the panel frequently rated PTCA as inappropriate. Panel scores were also affected by nonclinical factors. Cardiologists and surgeons rated the procedure of their own specialty higher than the alternative invasive intervention.

Conclusions-The panel method yields logically consistent scores of the appropriateness of indications for carrying out medical procedures. It may be an aid in formulating clinical practice guidelines.

(Heart 1997;77:211-218)
Keywords: coronary artery bypass grafting; percutaneous transluminal coronary angioplasty; indications; appropriateness

The provision of "appropriate care" has been a priority on the political agenda in The Netherlands since 1992, when the government published a white paper on the subject, but there is confusion among policy makers about what it means. ${ }^{1}$ We consider care appropriate when the benefits of using a medical procedure exceed the risks, exclusive of monetary cost. $^{23}$ Central to determining appropriateness of care is identifying appropriate reasons, or indications, for carrying out the procedure. Determining the appropriateness of indications is not seen in The Netherlands as a tool for health insurance companies to limit the cost of health care, but primarily as an aid for physicians and other health care workers to verify and enhance the quality of their professional decisions.

Assessments of the appropriateness of indications should ideally be based on the evidence in published work on the risks and benefits of applying the procedure. Unfortunately, for most procedures there are many possible indications for which this information is incomplete, inconsistent, or out of date. A commonly used method for dealing with the deficiencies of outcome results in the literature is the RAND/UCLA appropriateness method, which requires a panel of experts to review the published reports thoroughly and then to rate, in two rounds, the appropriateness of indications for carrying out a medical procedure. This method presumes that experienced physicians can use clinical insights to supplement the published reports. ${ }^{2-4}$ Panel scores can be used to evaluate the appropriateness of treatment decisions in everyday practice.

The RAND/UCLA method has been applied to a variety of medical procedures. ${ }^{46}$ Since 1988 panels in the USA, the United Kingdom, The Netherlands, Canada, and Sweden have determined the appropriateness of indications for coronary artery bypass graft (CABG) surgery and percutaneous transluminal coronary angioplasty (PTCA) for patients with coronary artery disease ${ }^{6-10}$ We describe here the views of the Dutch panel. In addition, we present findings from analyses aimed at identifying clinical and non-clinical determinants of the panel scores. In a second paper ${ }^{11}$ we report on the appropriateness of treatment decisions in coronary artery disease, in 10 tertiary referral centres in The Netherlands. This 
work is part of the DUCAT (Dutch inventory of invasive coronary atherosclerosis treatments) study. ${ }^{1213}$

\section{Methods \\ PANEL \\ In The Netherlands invasive cardiovascular interventions such as CABG and PTCA are carried out exclusively in specialised heart cen- tres on the basis of a permit issued by the gov- ernment. At the start of the DUCAT study, in 1991, there were 12 heart centres, seven form- ing part of university hospitals and five of non- university hospitals. We asked 12 prominent experienced clinicians, one from each centre, to participate in the panel. They all accepted the invitation. Six (including the only woman) were cardiopulmonary surgeons and six were interventional cardiologists. Unlike similar panels in the USA, Canada, and Sweden ${ }^{7-10}$ our panel did not include internists or primary care practitioners, as these physicians usually do not refer patients to heart centres in The Netherlands. The panelists varied in age (34-53 years), number of years since specialist registration (3-19), and school of specialist training, but not in volume of invasive cardio- vascular procedures personally performed (at least 100 in 1991). They were instructed to give their best personal clinical judgement and not to try to represent the position of their centre or specialty. The panelists took part in all steps of the RAND/UCLA method. They were provided with reviews of publications from 1971 to 1991 on the effectiveness and risks of CABG and PTCA, and with the report of the American College of Cardiology/ American Heart Association task force on bypass surgery..$^{78} 14$}

SET OF THEORETICAL INDICATIONS

A fundamental step in the RAND/UCLA method is to develop a comprehensive list of model cases. In drawing up the initial list we used as guides the reviews of published reports, experience from previous panels, and feedback from our panelists. We identified eight mutually exclusive "chapters" of model cases with significant coronary artery disease according to presenting symptoms or problems: (1) asymptomatic, (2) chronic stable angina, (3) unstable angina, (4) acute myocardial infarction, (5) recent myocardial infarction, (6) near sudden death, (7) CABG carried out with valve surgery, and (8) PTCA as palliative treatment in patients with non-cardiac terminal disease. (For definitions see the appendix.) Within each clinical chapter, model cases were characterised by unique combinations of clinical features in terms of symptoms, medical history, and the results of diagnostic tests. Although the chapters defined were identical to those identified by panels in other countries, ${ }^{7-10}$ the panels did not end up with exactly the same number of model cases and indications because of generally minor differences in number of clinical features, and number of levels per feature, selected.

An example of a model case is a patient with chronic stable angina on mild exertion (that is, Canadian Cardiovascular Society class III), who is receiving adequate medication (that is, a $\beta$ blocker, calcium channel antagonist, and nitrate, unless contraindicated), has two-vessel disease not including the proximal left anterior descending artery (PLAD) with at least one stenosis being a type $C$ lesion, ${ }^{15}$ has evidence of $\frac{T}{D}$ ischaemia on an exercise stress test, has severe left ventricular dysfunction, and is at high risk $\overrightarrow{\vec{B}}$ for significant postoperative complications $\stackrel{0}{\rightarrow}$ according to the Parsonnet index. ${ }^{16}$ Examples of type $C$ lesions are stenoses longer than $20 \frac{\bar{\sigma}}{\bar{N}}$ $\mathrm{mm}$, or with rugged contours or tortuous $\frac{\widehat{\phi}}{\vec{\alpha}}$ shape, or located at spots not readily accessible $a$ for a catheter, or total vessel occlusions older के than three months. For other definitions see $\overrightarrow{0}$ the appendix.

For most model cases the DUCAT panel $\vec{\omega}$ rated three indications, presented as a choice between two treatments, namely: (1) CABG $v ?$ medical treatment, (2) PTCA $v$ medical treatment, and (3) CABG $v$ PTCA. For the chap- iv ters "CABG with valve surgery" and "palliative PTCA", the panel rated only CABG $v$ medical 을 treatment and PTCA $v$ medical treatment, respectively. There were 1658 model cases and $\bar{s}$ 4890 indications in the initial round of ratings.

Sheets were prepared on which the panelists could rate each indication on a scale ranging $\notin$ from 1 (extremely inappropriate) to 9.7 (extremely appropriate). The sheets, which 응 had the form of a long tabular list with the rows presenting model cases and individual cells the indications, were mailed to the panelists, who individually completed the ratings $\stackrel{\mathbb{Q}}{2}$ (round 1). One and a half months later, in $\overrightarrow{0}$ August 1991, the panelists convened for a two 3 day meeting (round 2) to discuss issues emanating from round 1 and to rerate the indications confidentially. In both rounds the panelists were instructed to rate each indication keeping in mind average cases in the average practice in the heart centres in The Netherlands. That practice implies that refer- $\delta$ ring cardiologists who have diagnosed coronary artery disease in a patient present the $ᄋ$ findings, including the coronary angiogram, to an interventional cardiologist or cardiopulmonary surgeon or both. This presentation may be made either in person or by referral letter or telephone.

The results of round 1 were precirculated $\tilde{\omega}$ before the DUCAT panel met for round 2 . Each panelist received, for each indication, the 0 anonymous ratings of all the other panelists, $\mathbb{D}$ along with a reminder of his or her own rating. ? During the panel meeting the indications were $\frac{0}{0}$ discussed, concentrating on areas where the $\vec{D}$ panelists disagreed. The primary purpose of $\frac{\rho}{\mathbb{Q}}$ the discussion was to ensure that panelists had a $\stackrel{\square}{2}$ shared understanding of the type of cases described. Thus any remaining disagreements 8 would represent different treatment philosophies. The panel refined some of the defini- 흘 tions and revised the indications list, leaving a total of 1182 model cases and 3446 indications. After discussing each clinical chapter, the panelists rated anew the appropriateness of each indication. 
Three months after the panel meeting, the panelists were sent a set of indications (66 in total) randomly selected from the first six clinical chapters. The panelists were asked to rerate these indications in the same way as they had done in round 2. Eleven panelists returned the completed rating sheets.

\section{ANALYSIS}

The ratings were analysed on two partly interdependent dimensions: degree of agreement among panelists and degree of appropriateness. The scale was divided into three 3-point regions, 1-3, 4-6, and 7-9. Agreement was defined as at least nine of the ratings laying in one of these regions. By definition there was disagreement if the ratings of the panelists were split, with four or more falling in each of the two outer regions. In all other cases, the panel was said to be indeterminate. The appropriateness score for each indication was taken as the median of the ratings of the panelists. ${ }^{599}$ When comparing CABG or PTCA with medical treatment, the invasive treatment was appropriate if the median score was 7 to 9 , inappropriate if the median score was 1 to 3, and uncertain if that score was 4 to 6 or if there was disagreement among the panelists. For CABG $v$ PTCA indications the appropriateness score 7 to 9 meant that surgery was preferred to angioplasty, and 1 to 3 that angioplasty was preferred. Ratings and reratings were defined as matching each other if they lay in the same 3-point region. Test-retest concordance was assessed with the $\kappa$ statistic. ${ }^{17}$

Comparison of the scores between the two rounds was only done on indications common to both rounds. The analysis was restricted to clinical chapters 1 to 6 , that is, the chapters with all three sets of indications. The results of the comparison were displayed in $3 \times 3$ contingency tables and analysed with the test of marginal symmetry. ${ }^{18}$

Clinical and non-clinical determinants of appropriateness scores were assessed for each chapter with the least squares regression model, with the median of the ratings of the panelists, or subset of panelists, being the dependent variable for each indication.

\section{Results}

Although no attempt was made to reach consensus, agreement among the panelists increased from $48 \cdot 1 \%$ for the PTCA $v$ medical treatment indications in round 1 to $61.7 \%$ in round 2 , partly as a result of improved understanding of the rating process. ${ }^{19}$ Conversely, disagreement for these indications fell from $7.9 \%$ to $3.8 \%$ and indetermination from $48 \cdot 6 \%$ to $34 \cdot 5 \%$. Similar changes occurred for the two other sets of indications, CABG $v$ medical treatment and CABG $v$ PTCA $\left(\chi^{2}=\right.$ 161.7 ; df $2 ; P<0.001)$. For the three sets together the DUCAT panel agreed in round 2 on $58.6 \%$ and disagreed on $3.2 \%$ of the indications. Appropriateness scores also changed from round 1 to round 2, although to a lesser degree (for the three sets of indications together, $\chi^{2}=41.4 ;$ df $\left.2 ; \mathrm{P}<0.001\right)$. The number of indications where CABG or PTCA was judged appropriate compared with medical therapy rose by approximately $4.5 \%$ in both cases, while the number where CABG or PTCA was considered inappropriate decreased by $2 \cdot 0 \%$ and $1 \cdot 5 \%$, respectively. The number of CABG $v$ PTCA indications with clear preference for either surgery or angioplasty increased by $2 \cdot 4 \%$.

Test-retest concordance for the sample of 66 indications was significant $(\kappa=0.72$; $P<0.001)$. Ten retest scores differed from the original scores by 2 points, the maximum difference seen.

In the second round of ratings, CABG was considered appropriate when compared with medical treatment in $35.4 \%$ and inappropriate in $36.5 \%$ of the cases. The corresponding figures for PTCA were less favourable: $21 \cdot 6 \%$ appropriate and $55.4 \%$ inappropriate. Appropriateness scores varied by clinical chapter (table 1). For clinical chapters where both CABG and PTCA were considered, appropriateness scores were highest for predominantly urgent conditions: unstable angina, acute myocardial infarction, and near sudden death. Performing these procedures was considered inappropriate in many of the cases which were asymptomatic, had chronic stable angina, or had a recent myocardial infarction.

Table 1 Appropriateness of indications for coronary revascularisation and preferred treatment by clinical chapter

\begin{tabular}{|c|c|c|c|c|c|c|}
\hline \multirow[b]{2}{*}{ Chapter ${ }^{(a)}$} & \multicolumn{2}{|c|}{$C A B G v M E D$ indications } & \multicolumn{2}{|c|}{$P T C A$ v MED indications } & \multicolumn{2}{|c|}{ Preferred treatment\# } \\
\hline & Appropriate & Inappropriate & Appropriate & Inappropriate & Invasive & Medical \\
\hline $\begin{array}{ll}1 & \text { Asymptomatic (96) } \\
2 & \text { Chronic stable angina (480) } \\
3 \text { Unstable angina (144) } \\
4 \text { Acute myocardial }\end{array}$ & $\begin{array}{l}30 \cdot 2 \% \\
24 \cdot 8 \% \\
57 \cdot 6 \%\end{array}$ & $\begin{array}{l}53 \cdot 1 \% \\
48 \cdot 8 \% \\
13 \cdot 2 \%\end{array}$ & $\begin{array}{r}7 \cdot 3 \% \\
14 \cdot 8 \% \\
40 \cdot 3 \%\end{array}$ & $\begin{array}{l}77 \cdot 1 \% \\
59 \cdot 8 \% \\
36 \cdot 8 \%\end{array}$ & $\begin{array}{l}35 \cdot 4 \% \\
34 \cdot 4 \% \\
78 \cdot 5 \%\end{array}$ & $\begin{array}{r}41 \cdot 7 \% \\
31 \cdot 9 \% \\
2 \cdot 8 \%\end{array}$ \\
\hline $\begin{array}{l}\text { infarction (68) } \\
5 \text { Recent myocardial }\end{array}$ & $39 \cdot 7 \%$ & $16 \cdot 2 \%$ & $35 \cdot 3 \%$ & $22 \cdot 1 \%$ & $64 \cdot 7 \%$ & $5 \cdot 9 \%$ \\
\hline $\begin{array}{ll}\text { infarction (248) } \\
6 \text { Near sudden death (96) } \\
7 \text { CABG and valve surgery (2) } \\
8 \text { Palliative PTCA (48) }\end{array}$ & $\begin{array}{r}36 \cdot 3 \% \\
53 \cdot 1 \% \\
100 \cdot 0 \% \\
-\end{array}$ & $\begin{array}{r}36 \cdot 7 \% \\
8 \cdot 3 \% \\
0 \cdot 0 \% \\
-\end{array}$ & $\begin{array}{l}14 \cdot 1 \% \\
29 \cdot 2 \% \\
66 \cdot 7 \%\end{array}$ & $\begin{array}{l}65 \cdot 7 \% \\
57 \cdot 3 \% \\
16 \cdot 7 \%\end{array}$ & $\begin{array}{r}44 \cdot 4 \% \\
72 \cdot 9 \% \\
100 \cdot 0 \% \\
66 \cdot 7 \%\end{array}$ & $\begin{array}{l}25 \cdot 8 \% \\
4 \cdot 2 \% \\
0.0 \% \\
0.0 \%\end{array}$ \\
\hline Total $(1182)$ & $35 \cdot 4 \%$ & $36 \cdot 5 \%$ & $21 \cdot 6 \%$ & $55 \cdot 4 \%$ & $48 \cdot 2 \%$ & $22 \cdot 8 \%$ \\
\hline
\end{tabular}

Tata are percentages of the total number of indications for either CABG $v$ medical therapy, PTCA $v$ medical treatment, or

preferred treatment. Number of model cases in parentheses.
\#Invasive treatment was preferred to medical treatment when CABG and/or PTCA were rated appropriate. Medical treatment was preferred when both CABG and PTCA were rated inappropriate.

${ }^{\circledR}$ Clinical chapters were defined by presenting symptoms or problems. For definitions see Appendix.

-Not applicable.

CABG, coronary artery bypass grafting; MED, medical treatment; PTCA, percutaneous transluminal coronary angioplasty. 
The fact that CABG and PTCA were frequently rated inappropriate when compared with medical treatment does not necessarily imply that the panel preferred medical treatment. There were many model cases for which the panel judged CABG to be inappropriate but PTCA appropriate, or the other way round. In these cases, and when both CABG and PTCA were rated appropriate, the panel obviously preferred invasive treatment to medical treatment. On the other hand, medical treatment was preferred to invasive treatment when both CABG and PTCA were rated inappropriate for a model case. Overall the panel opted for invasive treatment in $48.2 \%$ of the model cases, while medical treatment was preferred in $22.8 \%$ of the cases. For the remaining $29.0 \%$ of the model cases the panel did not express a preference for either invasive treatment or medical treatment (table 1).

As anatomical disease became more severe in the model cases, the panel increasingly preferred invasive treatment to medical treatment (table 2). The panel opted for invasive treatment in $18.0 \%$ of the model cases with onevessel disease not including the PLAD, compared with $94 \cdot 0 \%$ of the cases with left main disease. One-vessel disease involving the PLAD was seen as a stronger reason for invasive treatment than two-vessel disease not involving the PLAD. At the same time the number of cases where medical treatment was preferred decreased as vessel disease became more severe, from $51.5 \%$ in one-vessel disease not including the PLAD to $0 \%$ in left main disease. Table 3 shows the preference of the panel for CABG or PTCA in model patients for whom invasive treatment was preferred to

Table 2 Panel's preference for invasive or medical treatment by level of anatomical disease

\begin{tabular}{lccl}
\hline & \multicolumn{2}{l}{ Preferred treatment } \\
\cline { 2 - 4 } Anatomical disease & Invasive & Medical & None \\
\hline One-vessel, - PLAD & $36(18 \cdot 0)$ & $103(51 \cdot 5)$ & $61(30 \cdot 5)$ \\
One-vessel, + PLAD & $80(40 \cdot 0)$ & $59(29 \cdot 5)$ & $61(30 \cdot 5)$ \\
Two-vessel, - PLAD & $52(26 \cdot 0)$ & $71(35 \cdot 5)$ & $77(38 \cdot 5)$ \\
Two-vessel, + PLAD & $99(49 \cdot 5)$ & $30(15 \cdot 0)$ & $71(35 \cdot 5)$ \\
Three-vessel & $110(65 \cdot 5)$ & $2(1 \cdot 2)$ & $56(33 \cdot 3)$ \\
Left main & $158(94 \cdot 0)$ & $0(0 \cdot 0)$ & $10(6 \cdot 0)$ \\
\hline
\end{tabular}

Numbers (\%) of model cases for which the panel opted for invasive or medical treatmen Invasive treatment was preferred to medical treatment when CABG and/or PTCA were rated appropriate. Medical treatment was preferred when both CABG and PTCA were rated inappropriate. None of the treatments was preferred if neither invasive nor medical treatment was preferred to the other treatment.

CABG, coronary artery bypass grafting; PTCA, percutaneous transluminal coronary angiopABG, coronary artery bypass grafting; PTCA, percutane with and withous descending coronary artery, respectively.

Table 3 Panel's preference for CABG or PTCA, or equally for both, by level of anatomical disease $\uparrow$

\begin{tabular}{lcrrr}
\hline \multicolumn{5}{l}{ Preference } \\
\cline { 2 - 5 } Anatomical disease & $n$ & $C A B G$ & \multicolumn{1}{l}{ PTCA } & \multicolumn{1}{c}{ Both } \\
\hline One-vessel, - PLAD & 36 & $0 \cdot 0 \%$ & $97 \cdot 2 \%$ & $2 \cdot 8 \%$ \\
One-vessel, + PLAD & 80 & $6 \cdot 3 \%$ & $75 \cdot 0 \%$ & $18 \cdot 8 \%$ \\
Two-vessel, - PLAD & 52 & $7 \cdot 7 \%$ & $78 \cdot 8 \%$ & $13 \cdot 5 \%$ \\
Two-vessel, + PLAD & 99 & $29 \cdot 3 \%$ & $44 \cdot 4 \%$ & $26 \cdot 3 \%$ \\
Three-vessel & 110 & $65 \cdot 7 \%$ & $0 \cdot 0 \%$ & $34 \cdot 3 \%$ \\
Left main & 158 & $98 \cdot 7 \%$ & $0 \cdot 0 \%$ & $1 \cdot 3 \%$ \\
\hline
\end{tabular}

ILimited to model cases $(\mathrm{n}=$ number) for which the panel preferred invasive treatment to medical treatment. "Both": cases where both CABG and PTCA were appropriate compared with medical treatment and where CABG was not preferred to PTCA or vice versa.

CABG, coronary artery bypass grafting; PTCA, percutaneous transluminal coronary angioplasty; + PLAD and - PLAD, with and without involvement of the proximal left anterio descending coronary artery, respectively. medical treatment. There was near absolute preference for surgery in left main disease, while the panel had few doubts that PTCA was to be preferred in one-vessel disease. In two-vessel disease angioplasty was favoured, particularly in cases without PLAD stenosis.

CLINICAL FACTORS BEARING ON PANEL SCORES The aggregate figures presented so far provide only limited insight into the considerations underlying the appropriateness scores. के Therefore we developed regression models to explain the median panel ratings. For brevity we only present the results for the three sets of 480 indications for the model cases with chronic stable angina (table 4). Severity of क coronary artery disease, anginal symptoms, $\overrightarrow{0}$ extent of medical treatment, and degree of peri-interventional risk were significantly $\vec{\omega}$ related to appropriateness scores for all three sets of indications. For CABG $v$ medical treat- ? ment indications the lesion characteristic of the coronary artery stenosis (type A, B, or C) iv made no difference, in contrast to both PTCA $v$ medical treatment and CABG $v$ PTCA indications. The outcome of an exercise stress test and the degree of left ventricular dysfunction were important for choosing between either type of invasive intervention and medical treatment, but they were not significant factors $\vec{\theta}$ for choosing between CABG and PTCA.

To illustrate the data in table 4 we take as an example a model patient who suffers from two-vessel disease not including the PLAD, has class II angina, is on adequate medication, has a positive exercise stress test, who does not $\stackrel{\mathbb{D}}{\Omega}$ have severe left ventricular dysfunction (that $\overrightarrow{\overrightarrow{0}}$ is, ejection fraction is $\geqslant 20 \%$ ), and whose risk $\frac{3}{3}$ of significant peri-interventional complications is not high. For this case both CABG and PTCA were rated uncertain when compared with medical treatment, that is, the appropriateness score lay in the middle range (4 to 6) of the rating scale (see "constant" in table 4). For CABG $v$ medical treatment indications 8 the appropriateness score was 4.8 regardless of $₹$ lesion type. Lesion type did matter in PTCA $v$ 의 medical treatment indications, the score being $5 \cdot 8$ if the lesion was type $A$ or $B$ and $2 \cdot 7$ 을 $(5 \cdot 8-3 \cdot 1)$ if type C. If an invasive procedure was to be done, the DUCAT panel preferred PTCA to CABG, as suggested by the constant $N$ score of $2 \cdot 8$. When the model case had left $\mathrm{N}$ main disease preference swayed to CABG $(2 \cdot 8$ 웅 $+5 \cdot 0=7 \cdot 8$ ), while in one-vessel disease the 0 score fell by $0 \cdot 7$ points $(2 \cdot 8-0 \cdot 7=2 \cdot 1)$.

NON-CLINICAL FACTORS

Appropriateness scores were also affected by non-clinical factors. Age, years since specialist $\stackrel{\odot}{\Phi}$ registration, and school of specialist training of $\stackrel{\mathbb{Q}}{\varrho}$ the panelists did not influence the scores, but specialty (surgeon or cardiologist) did. 8 Summed over all of the clinical chapters, sur- 을 geons rated slightly more CABG $v$ medical treatment indications appropriate than cardiologists $\left(37.3 \% v 34.9 \% ; \chi^{2}=5.65 ; \mathrm{P}<0.01\right)$ and slightly fewer of these indications inappropriate $\left(34.2 \% \quad v \quad 37.3 \% ; \chi^{2}=6.92\right.$; $\mathrm{P}<0.001)$. The two specialties differed most 
Table 4 Clinical determinants of appropriateness scores for treatment indications for chronic stable angina cases

\begin{tabular}{|c|c|c|c|}
\hline \multirow[b]{2}{*}{ Clinical factor } & \multicolumn{3}{|c|}{ Regression coefficient ${ }^{a}(95 \%$ CI) } \\
\hline & $C A B G v M E D$ & $P T C A v M E D$ & $C A B G v P T C A$ \\
\hline $\begin{array}{l}\text { Anatomy\#: } \\
\text { one-vessel, - PLAD } \\
\text { one-vessel, + PLAD } \\
\text { two-vessel, - PLAD } \\
\text { two-vessel, - PLAD } \\
\text { three-vessel } \\
\text { left main }\end{array}$ & $\begin{array}{l}-1.3(-1.9 \text { to }-1.6) \ddagger \\
0.4(0.2 \text { to } 0.7) \\
-1.6(1.4 \text { to } 1.9) \ddagger \\
3.0(2.7 \text { to } 3.3) \\
5.5(5.3 \text { to } 5.8) \ddagger\end{array}$ & $\begin{array}{l}0.0 \\
0.9(0.6 \text { to } 1.1) \ddagger \\
0.5(0.3 \text { to } 0.8) \ddagger \\
0.0 \\
-1.6(-1.8 \text { to }-1.3) \ddagger\end{array}$ & $\begin{array}{l}-0.7(-0.9 \text { to }-0.5) \ddagger \\
-0.7(-0.9 \text { to }-0.4) \ddagger \\
-\quad \\
0.5(0.3 \text { to } 0.8) \ddagger \\
2.7(2.5 \text { to } 3.0) \ddagger \\
5.0(4.7 \text { to } 5.2) \ddagger\end{array}$ \\
\hline $\begin{array}{l}\text { Lesion type: } \\
\text { A or Bף } \\
\text { C }\end{array}$ & $\overline{0} \cdot 0$ & $-\overline{3} \cdot 1(-3.3$ to -2.9$) \ddagger$ & $\overline{2} \cdot 6(2 \cdot 5$ to $2 \cdot 7) \ddagger$ \\
\hline $\begin{array}{l}\text { Anginal symptoms: } \\
\text { absent or I } \\
\text { II }^{\star} \\
\text { III or IV }\end{array}$ & $\begin{array}{c}-1.3(-1.5 \text { to }-1.1) \ddagger \\
1.3(1.1 \text { to } 1.4) \ddagger\end{array}$ & $\begin{array}{l}-0.9(-1.1 \text { to }-0.7) \ddagger \\
1.1(0.9 \text { to } 1.3) \ddagger\end{array}$ & $\begin{array}{l}-0.2(-0.4 \text { to }-0.1) \ddagger \\
0.3(0.2 \text { to } 0.5) \ddagger\end{array}$ \\
\hline $\begin{array}{l}\text { Medication: } \\
\text { adequatef } \\
\text { not adequate }\end{array}$ & $-0.1(-1.1$ to -0.8$) \ddagger$ & $-\overline{-0.9}(-1.0$ to -0.7$) \ddagger$ & $\overline{-0.1}(-0.2 \text { to }-0.0)^{\star}$ \\
\hline $\begin{array}{l}\text { Exercise stress test: } \\
\text { positiveף } \\
\text { not positive }\end{array}$ & $\overline{-0.9}(-1.0$ to -0.7$) \ddagger$ & $\overline{-0.9}(-1.0$ to -0.7$) \ddagger$ & $\overline{0} \cdot 0(-0.1$ to $0 \cdot 1)$ \\
\hline $\begin{array}{l}\text { Left ventricular dysfunction: } \\
\text { not severe } \mathbb{\text { : }} \\
\text { severe }\end{array}$ & $-0.6(-0.7$ to -0.4$) \ddagger$ & $\overline{-0.3}(-0.5$ to -0.1$) \ddagger$ & $\overline{0} \cdot 0(-0.1$ to $0 \cdot 1)$ \\
\hline $\begin{array}{l}\text { Peri-interventional risk: } \\
\text { not high } \| \\
\text { high }\end{array}$ & $\overline{-0.8}(-0.9$ to -0.6$) \ddagger$ & $\overline{-0.3}(-0.5$ to -0.2$) \ddagger$ & $\overline{-0.2}(-0.4$ to -0.1$) \dagger$ \\
\hline Constant & $4 \cdot 8(4 \cdot 5$ to $5 \cdot 1)$ & $5 \cdot 8(5 \cdot 6$ to $6 \cdot 1)$ & $2 \cdot 8(2 \cdot 6$ to $3 \cdot 0)$ \\
\hline
\end{tabular}

TThe reference model case was characterised by the factor levels marked with this symbol, that is, a constant, two-vessel disease not involving the PLAD, type A or B lesions, angina class II, adequate medication, with the outcome of an exercise stress test pointing involving the PLAD, type A or B lesions, angina class II, adequate medication, with the outcome of an exercise stress test pointing
to ischaemia, no severe left ventricular dysfunction, and not at high peri-interventional risk. For the CABG $v$ medical treatment indito ischaemia, no severe left ventricular dysfunction, and not at high peri-interventional risk. For the CABG $v$ medical treatment indi-
cation (CABG-MED) this patient's appropriateness score would be: $4 \cdot 8+0+0+0+0+0+0+0=4 \cdot 8$. Scores for the reference case

represent values on a $1-9$ scale.

${ }^{a}$ Computed with multiple linear regression analysis, not truncated. All values are differences relative to the score of the reference case. $95 \% \mathrm{CI}=95 \%$ confidence interval. $\mathrm{R}^{2}$ values were $0.81,0.89$, and 0.91 for CABG $v$ medical treatment, PTCA $v$ medical treatment, and CABG $v$ PTCA indications, respectively.

\#+ PLAD and - PLAD, with and without involvement of the proximal lett anterior descending coronary artery, respectively $\star P<0.05,+P<0.01, \ddagger P<0.001$.

CABG, coronary artery bypass grafting; MED, medical treatment; PTCA, percutaneous transluminal coronary angioplasty.

CABG-MED, PTCA-MED, and CABG-PTCA: the three sets of indications.

regarding the PTCA $v$ medical treatment indications. Surgeons rated fewer of these indications appropriate and more of them inappropriate than cardiologists $(18.4 \% \quad v$ $25 \cdot 7 \%, \chi^{2}=59 \cdot 7$, and $59 \cdot 1 \%$ v $48 \cdot 8 \%, \chi^{2}=$ $84 \cdot 6$, respectively; $\mathrm{P}<0.001)$. On average surgeons were more critical of PTCA $v$ medical treatment indications than cardiologists were of CABG $v$ medical treatment indications.

Considering only clinical chapters $1-6$, the tendency of the surgeons to rate PTCA $v$ medical treatment indications lower than the cardiologists was significant for the chronic stable angina, unstable angina, acute myocardial infarction, and recent myocardial infarction chapters. The picture for CABG $v$ medical treatment indications was more variable. The surgeons rated these indications significantly higher than the cardiologists did for the clinical chapters "asymptomatic", "unstable angina", and "near sudden death", but lower for "chronic stable angina" and "acute myocardial infarction". The pattern of results for acute myocardial infarction was particularly noteworthy. Here the surgeons rated both PTCA $v$ medical treatment and CABG $v$ medical treatment indications lower than the cardiologists, which suggests that they had more doubts about the usefulness of any invasive intervention.

Surgeons and cardiologists differed most consistently in how they appraised CABG $v$ PTCA indications. We wondered if this difference depended on interactions between spe- cialty and clinical factors, owing to differences between surgeons and cardiologists in their appreciation of the importance of these factors. We tested for this possibility by carrying out for each clinical chapter two multiple regression analyses of CABG $v$ PTCA scores, one with and one without interaction terms, using the clinical factors defining the reference model cases as input variables. Table 5 describes the reference model cases and presents the results of the analyses without interaction terms. Surgeons rated CABG $v$ PTCA indications higher than cardiologists for all of the clinical chapters, suggesting stronger preference for CABG among surgeons or, in other words, stronger preference for PTCA among cardiologists if a procedure was to be done. In analyses using interaction terms the CABG $v$ PTCA scores of the surgeons were not significantly higher than those of the cardiologists for the chapters "asymptomatic" and "acute myocardial infarction", except for a subset of indications. Surgeons' scores were higher for model cases with one-vessel disease not involving the PLAD in the chapter "asymptomatic" and for model cases with cardiogenic shock in the chapter "acute myocardial infarction". For all other chapters the disparity in scores between surgeons and cardiologists remained significant when interaction terms were added to the regression models. However, this difference was not constant across subsets of indications in each chapter. In general there was little discrepancy in the scores of surgeons and cardiologists for model 
Table 5 Choosing between CABG and PTCA: regression analyses of difference in appropriateness scores between surgeons and cardiologists by clinical chapter

\begin{tabular}{ll}
\hline Clinical chapter & Difference \\
\hline 1 Asymptomatic & $0.54 \ddagger$ \\
2 Chronic stable angina & $0.57 \ddagger$ \\
3 Unstable angina & $0.59 \ddagger$ \\
4 Acute myocardial infarction & $0.92 \ddagger$ \\
5 Recent myocardial infarction & $0.82 \ddagger$ \\
6 Near sudden death & $0 \cdot 29^{\star}$ \\
\hline
\end{tabular}

ףDifferences in appropriateness scores expressed as values relative to the scores for the reference cases (that is, the constants of multiple regression analyses) on a 1-9 scale. The higher the difference, the stronger the preference for CABG
among surgeons or, in other words, the stronger the preference for PTCA among cardiologists.

for PTCA among cardiologists. Characteristics of reference model cases. Common to all cases:
two-vessel disease without involvement of the PLAD, type A two-vessel disease without involvement of the PLAD, type A
or B lesions, no severe left ventricular dysfunction, not at high risk for peri-interventional complications. Additional features: Asymptomatic, evidence of ischaemia on an exercise stress test. Chronic stable angina, angina class II, adequate medication, evidence of ischaemia on an exercise stress test. Unstable angina, pain on adequate medication. Acute myocardial infarction, continuing paint. Recent myocardial infarction, non$\mathrm{Q}$-wave infarction, asymptomatic, no evidence of ischaemia on an exercise stress test. Near sudden death, pain and/or evidence of ischaemia on an exercise stress test.

$\star P<0.05, \pm P<0.001$

CABG, coronary artery bypass grafting; PTCA, percutaneous transluminal coronary angioplasty; PLAD, proximal left anterior descending coronary artery.

cases with left main disease or three-vessel disease and for model cases with type $\mathrm{C}$ lesions. The greatest disparities were found for model cases with one-vessel disease, where the tendency of the surgeons to rate CABG $v$ PTCA indications higher than the cardiologists amounted to a $1 \cdot 5-2$ points difference on the 1-9 scale for the chapters "chronic stable angina" and "recent myocardial infarction".

Finally, we averaged for each of the panelists their ratings of all CABG $v$ medical treatment indications and all PTCA $v$ medical treatment indications. We then determined the rank order of the panelists for each set of indications, the one with the highest mean score being placed in the first and the one with the lowest score in the 12 th position. The results are shown in table 6 . Numbers 1 and 2 in the table, a cardiologist and a surgeon, ranked high on both sets of indications. These two clinicians can be said to favour, at least on paper, an aggressive practice style regardless of the type of invasive intervention. In contrast, members 11 and 12 made up the rear on both CABG $v$ medical treatment and PTCA $v$

Table 6 Rank order of panelists based on their average ratings of all indications involving a choice between $C A B G$ and medical treatment or between PTCA and medical treatment

\begin{tabular}{llcc}
\hline & \multicolumn{2}{l}{ Rank number } & \\
\cline { 2 - 4 } Panelist & $\begin{array}{l}\text { CABG-MED } \\
\text { indications }\end{array}$ & $\begin{array}{l}\text { PTCA-MED } \\
\text { indications }\end{array}$ & Sum $^{(}$ \\
\hline 1 Cardiologist & 3 & 1 & 4 \\
2 Surgeon & 2 & 4 & 6 \\
3 Cardiologist & 7 & 2 & 9 \\
4 Surgeon & 1 & 6 & 10 \\
5 Surgeon & 5 & 3 & 11 \\
6 Cardiologist & 9 & 7 & 11 \\
7 Surgeon & 4 & 10 & 13 \\
8 Cardiologist & 8 & 8 & 16 \\
9 Cardiologist & 6 & 11 & 22 \\
10 Surgeon & 10 & 12 & 24 \\
12 Sardiologist & 11 & & \\
\hline
\end{tabular}

TNumbers in order of sum total.

${ }^{\otimes}$ Sum of rank number for CABG indications and rank number for PTCA indications.

CABG, coronary artery bypass grafting; MED, medical treatment; PTCA, percutaneous trans luminal coronary angioplasty. medical treatment indication ratings, which may correspond to a conservative style. Other panel members, such as panelists 3,4 , and 6 , ranked high on the indications involving the invasive intervention from their own specialty but lower on the other indications.

\section{Discussion}

We asked a Dutch expert panel to rate the appropriateness of indications for using CABG and PTCA in hundreds of model cases. Ideally, deciding whether indications are appropriate or not should be based on the outcomes of randomised clinical trials. However, we cannot expect trials with their क strict selection of patients to address all clini- $\vec{\circ}$ cal permutations with sufficient precision to provide guidance about how to treat all of the cases seen in practice. Inevitably, physicians must also rely on clinical judgement and inference. This is not to excuse physicians from scrutinising and testing the effects of their actions. Rendering clinical judgement explicit should be integral to the practice of medicine. The RAND/UCLA method provides a feasible tool for this purpose.

The method may have limitations though. One could wonder whether panelists are able to rate large numbers of indications reliably and consistently. The evidence is that panelists are up to this task. In our study there was satisfactory test-retest concordance for a random sample of indications and others also have found panel scores to be reliable. ${ }^{5}$ A potential problem with group judgement methods is the risk that the outcomes are biased by collective error. This leads us to the issue of validity. Construct validity reflects the degree to which the features used to describe model cases are relevant for clinical practice. The list of model cases for CABG and PTCA appears to have good construct validity. Not only did panels in various countries select largely the same set of clinical features, ${ }^{7-10}$ but an analysis of treatment decisions in everyday practice also showed that these and a few additional features indeed influenced if not determined clinicians' decision making. ${ }^{11} 19$ Moreover, the scores of the DUCAT panel corresponded well to clinical guidelines developed concur- o rently but independently on behalf of the $N$ Netherlands Society of Cardiology. ${ }^{20}$ Content $\mathrm{N}$ validity is the degree in which the panel scores accurately reflect the appropriateness of indi- 0 cations. There were no clear discrepancies between the evidence in published reports at the time of the panel meeting on the one hand $T$ and the DUCAT panel scores on the other. The key question is how valid the scores were in the many cases where the evidence was incomplete. One way to answer this question is to look at research data that became available after the DUCAT panel met.

Since the panel meeting in 1991, results of several randomised trials comparing PTCA with medical treatment and PTCA with CABG have been published. ${ }^{21-27}$ In the ACME trial coronary angioplasty was better than medical treatment in relieving angina at six 
months' follow up and improving exercise tolerance in patients with one-vessel disease. ${ }^{21}$ It remains to be seen whether these modest benefits outweigh the procedure related complications of PTCA. The DUCAT panel favoured medical treatment in one-vessel disease without PLAD stenosis. A meta-analysis of results from trials comparing PTCA with CABG in patients with either one-vessel or multivessel disease failed to show a treatment difference in rates of death and non-fatal myocardial infarction during up to three years' follow up. ${ }^{28}$ However, patients in the PTCA groups more often had angina, took more antianginal drugs, and required further revascularisation more frequently. All investigators nevertheless agreed that PTCA remains a suitable option and a simple initial alternative to CABG. ${ }^{22-27}$ This conclusion does not run counter to the opinions of the DUCAT panel. The panel predominantly preferred PTCA to CABG in oneand two-vessel disease, and CABG to PTCA in three-vessel disease (table 3). It should be noted, though, that the indications rated by the panel were not weighted for frequency of occurrence in actual practice. Consequently, these findings do not necessarily represent the proportion of cases that would be found appropriate or inappropriate in everyday practice.

Another issue is PLAD stenosis. The panel considered PLAD stenosis to be important for deciding between treatments. It more often opted for invasive treatment in cases with onevessel disease with PLAD stenosis than in twovessel disease not including the PLAD (table 2). A review of the 10 year results from randomised trials comparing CABG with medical treatment, ${ }^{29}$ published after the panel meeting, suggests that the panel was right. The review renders it likely that patients with one-vessel disease involving the PLAD benefit more from surgery than those with two-vessel disease without PLAD stenosis.

Taken together the results from recent trials and meta-analyses support the views of the DUCAT panel. However, the evidence for how to treat many patients with coronary artery disease is still incomplete and will probably remain so. It is likely that the majority of model cases considered by the panel will never be the subject of externally valid randomised trials, and this is precisely why using appropriateness methods is potentially so important, for instance for formulating clinical practice guidelines.

The best way to assess the validity of the RAND/UCLA method is to relate panel scores to patient outcomes. So far this has mainly been done in retrospective studies in which the medical records of patients were searched for relevant information after the intervention had taken place. ${ }^{53031}$ Further proof of the validity of the method may come from prospective studies. One would expect patients with an appropriate decision to fare better after the intervention than similar patients with an inappropriate decision. ${ }^{32}$ Some evidence to this effect has come from a retrospective cohort study. ${ }^{33}$ The DUCAT project includes a prospective study of this sort.

The DUCAT panel scores were not free from bias. Bias is apparent from the impact of non-clinical factors such as the distinction between cardiologists and surgeons. Also in other panel studies physicians carrying out a procedure tended to rate indications for that procedure higher than those for alternative procedures. ${ }^{34}$ The importance of these nonclinical factors should not be exaggerated. Although the number of inappropriate indications might even have been higher if non-clinical factors had not been in effect, the DUCAT panelists considered many indications to be inappropriate. How one assesses the influence of non-clinical factors such as panel composition depends in part on the goals one wishes to accomplish with the RAND/UCLA method. ${ }^{35}$ One aim of DUCAT is to provide clinicians in The Netherlands with a decision aiding tool fit for use in the "bipartisan" (interventional cardiology and cardiac surgery) environment of specialised tertiary referral centres. As the practice of medicine continues to evolve, this tool can be used to trace and monitor changes in medical practice and to update professional policies regarding indication setting.

This work was part of the DUCAT (Dutch inventory of invasive coronary atherosclerosis treatments) study, funded by the sive coronary atherosclerosis treatments) study, funded by the National Health Insurance Board (Ziekenfondsraad) in The
Netherlands. The study design was approved by the medical ethics committee of the University Hospital Dijkzigt in Rotterdam. The panel members were J J R M Bonnier, T Ebels, J M P G Ernst, Th R van Geldorp, L A van Herwerden, G J Laarman, B A J M de Mol, N H J Pijls, K B Prenger, G L van Rijk-van Zwikker, P W Westerhof, and F Zijlstra.

\section{Appendix}

DEFINITIONS OF CLINICAL CHAPTERS

Asymptomatic, patients with significant coronary artery disease without a history of angina, or who have no angina on their current medical regimen for more than three months, or who have sustained a myocardial infarction more than 30 days ago with no recurrence of angina for at least three weeks.

Chronic stable angina, patients meeting three of four conditions: (1) substernal or left sided chest pain; (2) radiation of pain to the left arm, left side of the neck, or left jaw; (3) the pain is usually precipitated by exercise; (4) the pain is relieved within 10 minutes by rest or sublingual glyceryl trinitrate.

Unstable angina, chest pain thought to be due to myocardial ischaemia requiring hospital admission because of difficulty in control or concern about the possibility of myocardial infarction, including (1) recent increase in the intensity, frequency, or duration of chronic angina; (2) the development of angina at rest; or (3) new onset of severe chest pain

Acute myocardial infarction, infarction within 24 hours.

Recent myocardial infarction, infarction between 1 and 30 days.

Near sudden death, patients who are presumed to have sustained a cardiac arrest without evidence of a myocardial infarction.

$C A B G$ and valve surgery, bypass grafting done concurrently with valve surgery.

Palliative PTCA, PTCA as palliative treatment in patients with non-cardiac terminal disease who would not be considered candidates for bypass surgery in the event of PTCA failure.

CLINICAL CHARACTERISTICS NOT DEFINED IN THE TEXT OR IN CITED REFERENCES

Significant coronary artery disease, at least $50 \%$ stenosis in the left main artery; at least $70 \%$ stenosis in one artery in case of one-vessel disease; at least $70 \%$ stenosis 
in one artery and $50 \%$ in other arteries in case of multivessel disease.

Adequate medication, chronic stable angina: patient receives or has received drugs from three classes of medication: $\beta$ blockers, calcium channel antagonists, and long acting nitrates, or less as far as justified by the presence of contraindications; unstable angina: patien receives or has received drugs from the same three classes of medication and receives intravenous heparin and/or intravenous glyceryl trinitrate, unless contraindicated.

Severe left ventricular dysfunction, ejection fraction $<20 \%$.

Stress test, any exercise stress test or stress imaging study; positive outcome: ST depression equal or greater than $1 \mathrm{~mm}$ (exercise test), or total or partial reversible defect in one arterial territory (imaging study). The outcome of the stress test was considered to be "not positive" if the test was performed and had a negative or indeterminate result or if the test was not performed.

1 Rigter H. Passend gebruik van het begrip "gepast" in discussies over de gezondheidszorg. (Appropriate use of the concept "appropriate" in discussions about health care.) Ned Tijdschr Geneeskd 1994;138:4-7.

2 Chassin M. How do we decide whether an investigation or procedure is appropriate? In: Hopkins A, ed. Appropriate procedure is appropriate? In: Hopkins A, ed. Appropriate investigation and treatment in clinical prat

3 Brook RH, Chassin MR, Fink A, Solomon DH, Kosecoff J, Park RE. A method for the detailed assessment of the appropriateness of medical technologies. Int $\mathcal{f}$ Technol Assess Health Care 1986;2:53-63.

4 Kahan JP, Bernstein SJ, Leape LL, Brook RH. Measuring the necessity of medical procedures. Medical Care 1994;32:357-65

5 Park RE, Fink A, Brook RH, Chassin MR, Kahn KL Merrick NJ, et al. Physician ratings of appropriate indications for six medical and surgical procedures. Am $\mathcal{F}$ Public Health 1986;76:766-72.

6 Gray D, Hampton JR, Bernstein SJ, Kosecoff J, Brook RH. Audit of coronary angiography and bypass surgery. Lancet 1990;335:1317-20.

7 Hilborne LH, Leape LL, Kahan JP, Park RE, Kamberg CJ, Brook RH. Percutaneous transluminal coronary angioplasty: $A$ literature review and ratings of appropriateness and necessity. Santa Monica: The RAND Corporation 1991, publisity. Santa Monica
cation JRA-01.

8 Leape LL, Hilborne LH, Kahan JP, Stason WB, Park RE, Kamberg CJ. Coronary artery bypass graft: a literature review and ratings of appropriateness and necessity. Sant Monica: The RAND Corporation 1991, publication JRA-02.

9 Naylor CD, McGlynn EA, Leape LL, Pinfold SP, Bernstein SJ, Hilborne LH, et al. Coronary angiograph and revascularization: Defining procedural indication through formal group processes. Can $\mathcal{f}$ Cardiol 1994 10:41-8.

10 Johansson SR, Brorsson B, Bernstein SJ. Coronary artery bypass graft and percutaneous transluminal coronary angioplasty. Stockholm: The Swedish Council on Technolog Assessment in Health Care, 1994:SBU Report 120E.

11 Meijler AP, Rigter H, Bernstein SJ, Scholma JK, McDonnell J, Breeman A, et al. The appropriateness of intention to treat decisions for invasive therapy in coronary artery disease in The Netherlands. Heart 1997;77: 219-24.

12 Rigter H, Meijler AP, Breeman A, Sprenger ML, Bernstein SJ. DUCAT: an observational study of indication setting for intervention in patients with coronary artery disease. Neth $\mathcal{F}$ Cardiol 1992;5:131-6.

13 Meijler AP, McDonnell J, Rigter H. Beoordeling van indicatiestelling met de RAND-methode: invasieve therapie bij coronairsclerose als voorbeeld. (Evaluation of indication setting with the RAND method: the example of invasive therapy in coronary artery disease.) Ned Tijdschr Geneeskd 1994;138:22-8.
14 Subcommittee on coronary artery bypass graft surgery. American College of Cardiology/American Heart Association Task Force on assessment of diagnostic and therapeutic cardiovascular procedures. ACC/AHA guideline and indications for coronary artery bypass surgery
Circulation $1991 ; 83: 1125-73$.

15 Faxon DP, Holmes D, Hartzler G, King SB, Dorros G. ABC's of coronary angioplasty: have we simplified it too much? Cathet Cardiovasc Diagn 1992;25:1-3.

16 Parsonnet V, Dean D, Bernstein AD. A method of uniform stratification of risk for evaluating the results of surgery in acquired adult heart disease. Circulation 1989;79(supp 1):3-12.

17 Fleiss JL. Statistical methods for rates and proportions, 2nd ed. New York: John Wiley and Sons, 1988

18 Agresti A. Categorical data analysis. New York: John Wiley and Sons, 1990.

19 Rigter H, Meijler AP, Scholma J, McDonnell J, Breeman A. DUCAT. Passende indicaties voor behandeling van patiënten met coronairlijden. (Appropriate indications for treatment of patients with coronary artery disease). Rotterdam: Institutes for Medical Technology Assessment and of Public Health and Social Medicine, 1995:i. MTA report $95 \cdot 38$

20 Pijls NH, Bonnier JJRM, Witsenburg M, Hoedemaker G, Kiemeney F, Koolen JJ, et al. Interventional cardiology I. Techniques and indication. Guidelines Cardiol 1994;7: I. $1-12$.

21 Parisi AF, Folland ED, Hartigan P. A comparison of angioplasty with medical therapy in the treatment of singlevessel coronary artery disease. N Engl J Med 1992; 326:10-6.

22 Goy J-J, Eeckhout E, Burnand B, Vogt P, Staufter JC Hurni $M$, et al. Coronary angioplasty versus left internal mammary artery grafting for isolated left anterior descending artery stenosis. Lancet 1994;343:1449-53.

24 RITA trial participants. Coronary angioplasty versus coronary artery bypass surgery: the Randomised Intervention . 573-80.

24 Rodriguez A, Boullon F, Perez-Balino N, Paviotti C, Liprandi MI, Palacios IF. Argentine Randomized trial of percutaneous transluminal coronary angioplasty versus coronary artery bypass surgery in multivessel disease (ERACI): in-hospital results and 1-year follow-up. $\mathcal{F} \mathrm{Am}$ Coll Cardiol 1993;22:1060-7.

25 King SB, Lembo NJ, Weintraub WS, Kosinski AS, Barnhart HX, Kutner MH, et al. A randomized tria comparing coronary angioplasty with coronary bypass surgery. N Engl F Med 1994;331:1044-50.

26 Hamm CW, Reimers J, Ischinger T, Rupprecht HJ, Berger J, Bleifeld W. A randomized study of coronary angioplasty compared with bypass surgery in patients with pymptomatic multivessel coronary disease. $N$ Engl f Med 1994;331:1037-43.

27 CABRI Trial Participants. First-year results of CABR (Coronary Angioplasty versus Bypass Revascularisation (Coronary Angioplasty versus Bypass R

28 Pocock SJ, Henderson RA, Risckards AF, Hampton JR King SB, Hamm CW, et al. Meta-analysis of randomized trials comparing coronary angiography with bypass surgery. Lancet 1995;346:1184-9.

29 Yusuf S, Zucker D, Peduzzi P, Fisher LD, Takaro T, Kennedy JW, et al. Effect of coronary artery bypass graft surgery on survival: overview of 10-year results from randomised trials by the Coronary Artery Bypass Graft Surgery Trialists collaboration. Lancet 1994;344:563-70.

30 Bernstein SJ, Kosecoff J, Gray D, Hampton JR, Brook RH, et al. The appropriateness of the use of cardiovascular procedures. British versus U.S. perspectives. Int 7 Technol Assess Health Care 1993;9:3-10.

31 McClellan M, Brook RH. Appropriateness of care: comparison of global and outcome methods to set standards. Med Care 1992:30:565-86.

32 Phelps CE. The methodologic foundations of studies of the $N$ appropriateness of medical care. N Engl f Med 1993; 329:1241-5.

33 Kravitz RL, Laouri M, Kahan JP, Guzy P, Sherman T, N Hilborne $\mathrm{L}$, et al. Validity of criteria used for detecting $\mathrm{C}$ underuse of coronary revascularization. $¥ A M A$ 1995;274: $O$

34 Kahan JP, Park RE, Leape LL, Bernstein SJ, Hilborne LH, Parker $\mathrm{L}$, et al. Variations by specialty in physician ratings of the appropriateness and necessity of indications for procedures. Med Care 1996;34:512-23.

35 Naylor CD. Grey zones of clinical practice: some limits to evidence-based medicine. Lancet 1995;345:840-2. 